\title{
Reduction Design of IPMSM Torque Ripple using Design of Experimental
}

\author{
Do-hyun Kim¹, Dae-seong Kim¹, Hui-seong Shin ${ }^{1}$, Ki-chan Kim*² \\ ${ }^{1}$ Master's degree, Dept. of Electrical Eng., Hanbat National Univ., Daejeon 34158, Korea \\ ${ }^{*}$ Professor, Dept. of Electrical Eng., Hanbat National Univ., Daejeon 34158, \\ Korea rlaehgus9560@ naver.com ${ }^{1}$, king56986 @ naver.com ${ }^{1}$, gmltjd9850@ naver.com ${ }^{1}$, Kckim92@ hanbat.ac.kr²
}

Article History:Received:11 november 2020; Accepted: 27 December 2020; Published online: 05 April 2021

Abstract: In the internal permanent magnet synchronous motor (IPMSM), torque pulsation occurs under no load. This is called cogging torque, and this causes noise and vibration during startup. Use factorial design, one of the experimental designs (DoE), to find the level of the factor with the lowest cogging torque and harmonic distortion (THD). The level of the found factor is applied to the analysis model. The main factors in factorial design are the skew step and skew angle. Based on the optimal factor level found through factor design, we compared the waveforms of torque ripple and line voltage at the maximum speed and the base speed of the analysis model and the model to which the skew was applied through finite element analysis (FEM). As the skew was applied, the harmonics were reduced, thereby reducing the torque ripple, and the line voltage waveform was also applied to the skew, resulting in a smoother waveform.

Keywords: Design of Experiment, Total Harmonic Distort ion, IPMSM, Skew, Torque Ripple.

\section{Introduction}

Electric motors using permanent magnets are largely classified into two types. Surface mounted permanent magnet motors(SPMSM) that attach permanent magnets to the rotor surface are divided into interior permanent magnet synchronous motors(IPMSM) that buy permanent magnets into the rotor, and IPMSM are frequently used. However, in the case of IPMSM, a torque pulsation phenomenon called cogging torque occurs. [1-4]. Cogging torque affects vibration at starting and at low speeds and affects torque ripple. In addition, vibration and noise are generated and efficiency may be reduced. As a method of reducing the cogging torque There are many methods, such as increasing the length of the air gap, applying skew to the stator or rotor, increasing the number of slots or poles, using magnet with little magnetic flux density. [5-8]. There is this. The method of increasing the length of the pores has a poor magnetic flux density, which adversely affects the output. From a design point of view it's impossible to completely Weak cogging torque by the number of poles or slots. In general, rotor skew is applied to reduce cogging torque. [9-10].

In this paper, we use the general full factorial design, an experimental design method implemented in all combinations according to the level of the experimental factors. Based on the data obtained from the FEM, factors were selected using the skew angle of the rotor and the skew stage of the rotor, which affect the total harmonic distortion(THD) and cogging torque, which are the main causes of torque ripple, using the factorial design. The factorial design finds the level of the factor with the lowest harmonic distortion and cogging torque. It was found that the level of the coefficient was applied to the analysis model and torque ripple was reduced through FEM.

\section{Analysis Model}

The 15KW IPMSM for driving the ultra-compact electric vehicle studied in this paper was selected as the analysis model. The maximum torque is generated up to $65 \mathrm{Nm}$. In Figure 1, the $2 \mathrm{D}$ model is shown through FEM analysis of the analysis model. This analysis model has a structure of 4 poles and 36 slots, and the winding method is concentric

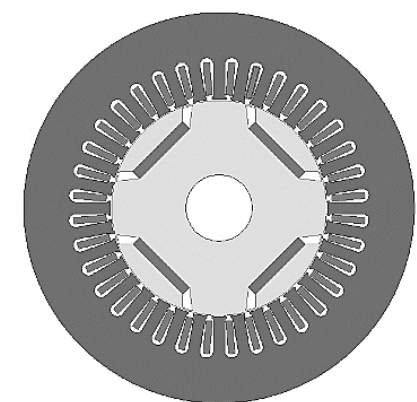

Figure 1. 15KW IPMSM FEM Model

Table 1 is the basic specifications of the analysis model for FEM. The maximum power of the motor

*Corresponding author: Ki-chan Kim

Professor, Dept. of Electrical Eng., Hanbat National Univ., Daejeon 34158,

Kckim92@ hanbat.ac.kr*2 
is $15 \mathrm{KW}$ and the battery voltage limit is $120 \mathrm{~V}_{\mathrm{dc}}$. The maximum torque is $65 \mathrm{~kW}$. The maximum torque is maintained at 2,200 rpm at the rated operating point, and then gradually decreases by controlling the weak magnetic flux while entering the constant power range up to the maximum speed of 5,600 rpm. Figure 2 shows the operational area of the analytical model. The solid line means instantaneous rating, and the dotted line means continuous rating.

Table 1: Specification of motor IPMSM for driving electric vehicles

\begin{tabular}{ccc}
\hline \hline Parameter & Quantity & Unit \\
\hline Max. Power & 15 & $\mathrm{KW}$ \\
Max. Torque & 65 & $\mathrm{Nm}$ \\
Battery limit voltage & 120 & $\mathrm{~V}_{d c}$ \\
Num. poles & 4 & \\
Num. slots & 48 & \\
Stator Outer Dia. & 175 & $\Phi$ \\
Rotor Outer Dia. & 92.8 & $\Phi$ \\
Stack Length & 129 & $\mathrm{~mm}$ \\
Speed(base/max) & $2,200 / 6,600$ & $\mathrm{rpm}$ \\
\hline
\end{tabular}

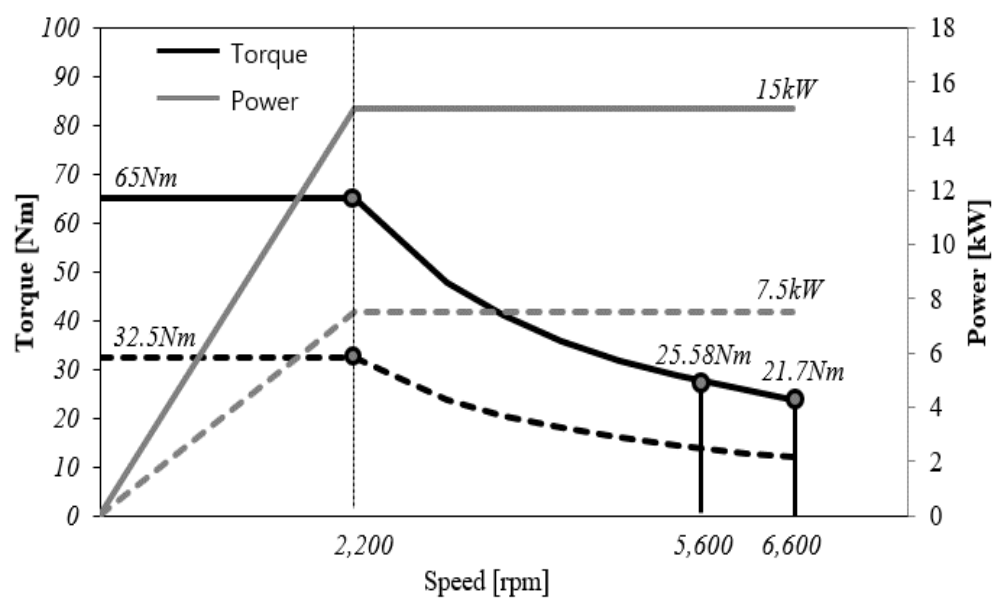

Figure 2. Operation region of model

\section{Optimization through factorial Design}

Generally, the $\mathrm{K}^{\mathrm{n}}$ factorial experimental method is an experimental design method in which the number of arguments is $\mathrm{n}$, and $\mathrm{k}$ is the number of levels of each factor. Experiments are performed with level combinations between all arguments. Therefore, even if the experiment is repeated, $\mathrm{K}^{\mathrm{n}}$ times of the experiment are performed. In the factorial experiment, the effect of the interaction with the main effect of the argument can be estimated. Table 2 is defined by the level from 1 degree to 10 degree consideration of the slot pitch with the skew angle level at no load (1,000 rpm), and the FEM is used by setting the skew step to 2 steps and 3 steps. The data of cogging torque and THD are shown.

Table 2: Characteristic value using FEM (a) 2nd skew (b) 3rd skew

(a)

\begin{tabular}{ccc}
\hline \hline $\begin{array}{c}\text { Skew } \\
\text { angle(deg) }\end{array}$ & $\begin{array}{c}\text { Cogging torque } \\
(\mathrm{Nm})\end{array}$ & $\begin{array}{c}\text { harmonic } \\
\text { distortion }(\%)\end{array}$ \\
\hline 1 & 1.26 & 12.2 \\
2 & 0.8728 & 10.93 \\
3 & 0.721 & 8.78 \\
4 & 0.7639 & 6.59
\end{tabular}


(b)

\begin{tabular}{ccc}
\hline \hline $\begin{array}{c}\text { Skew } \\
\text { angle(deg) }\end{array}$ & $\begin{array}{c}\text { Cogging torque } \\
(\mathrm{Nm})\end{array}$ & $\begin{array}{c}\text { harmonic distortion } \\
(\%)\end{array}$ \\
\hline 1 & 1.4099 & 12.9 \\
2 & 1.0535 & 11.89 \\
3 & 0.7587 & 10.33 \\
4 & 0.5728 & 8.45 \\
5 & 0.5364 & 6.55 \\
6 & 0.4084 & 5.12 \\
7 & 0.3026 & 4.57 \\
8 & 0.5471 & 4.83 \\
9 & 0.8947 & 5.27 \\
10 & 0.9964 & 5.34 \\
\end{tabular}

Figure 3 shows the THD and the main effect of cogging torque, which affects torque ripple. When looking at the main effect diagram of the THD, the distortion rate is the lowest when the skew is 3 steps and the skew angle is 6 degrees. Looking at the main effect of the cogging torque, the skew is the lowest when the skew is 3 steps and the skew angle is 7 degrees.

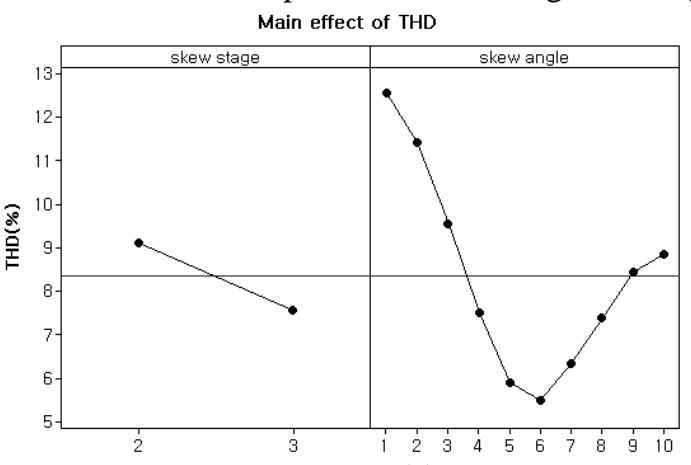

(a)

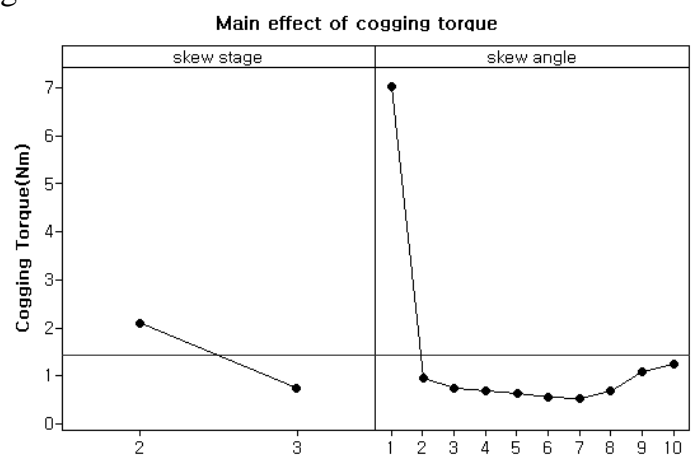

(b)

Figure 3. Main effect diagram using Design of experiments (a) THD (b) Cogging Torque

The factorial method was used to investigate the levels of the factors with the lowest THD and the lowest cogging torque. Figure 4 used the reaction optimization tool to find a more accurate optimal solution. In order to find the level of the factor with the THD and cogging torque, the smaller the characteristic value, the better the Manso characteristic is used. D means the overall satisfaction of the experiment and y means the predicted response value. Hi 2 is divided into 3 stages of skew and Lo is divided into 2 stages of skew. Cur represents the level of the factors at the lowest cogging torque and THD. Therefore, when the skew group has three stages and the skew angle is 7 degrees, the lowest characteristic value is shown. Figure 5 shows a model with skew applied to the magnet of the rotor. 


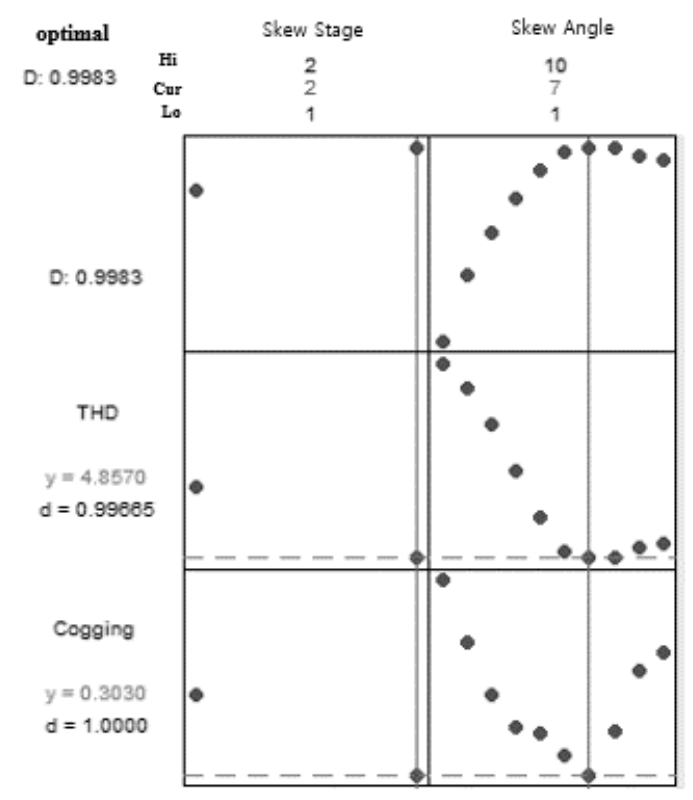

Figure 4. Derivation of the optimal solution for an analysis model using an optimization tool
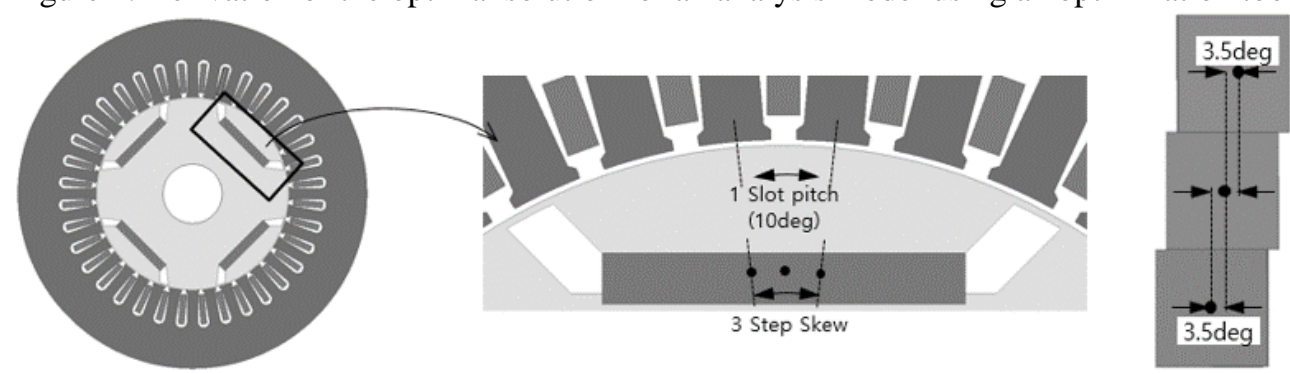

Figure 5. Model with skew applied to the magnet of the rotor

4. Comparison of an analysis model and skew applied model characteristics.

Figure 6 shows the torque waveform and the line voltage waveform of the base speed of the analysis model. Figure 7 shows the torque and line voltage waveforms of the skewed analysis model. If you compare the waveforms of the two models, you can see that the skewed model has a slight increase in torque and a reduction in torque ripple. In addition to the torque waveform, when the skew is applied, the voltage waveform also reduces harmonics, so that the voltage waveform shows a slightly smoother waveform [11].
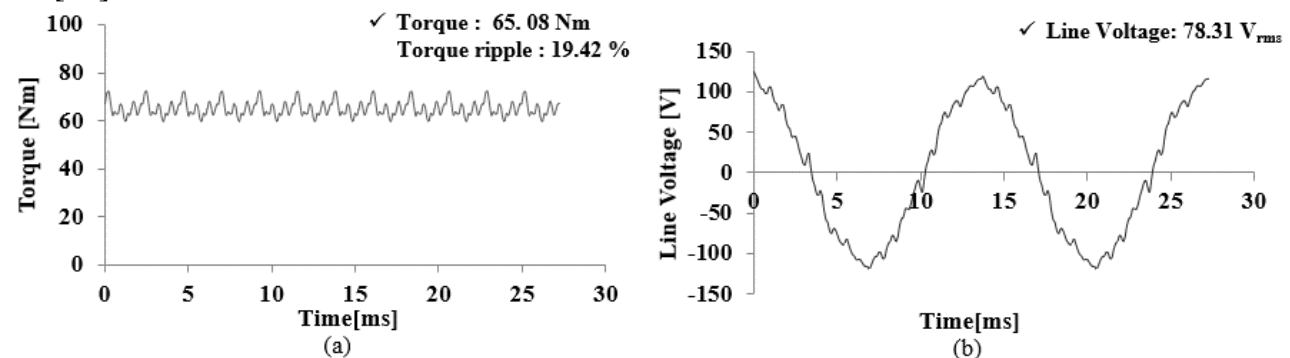

Figure 6. Wave of base model (2,200rpm) (a) Torque (b) Line Voltage
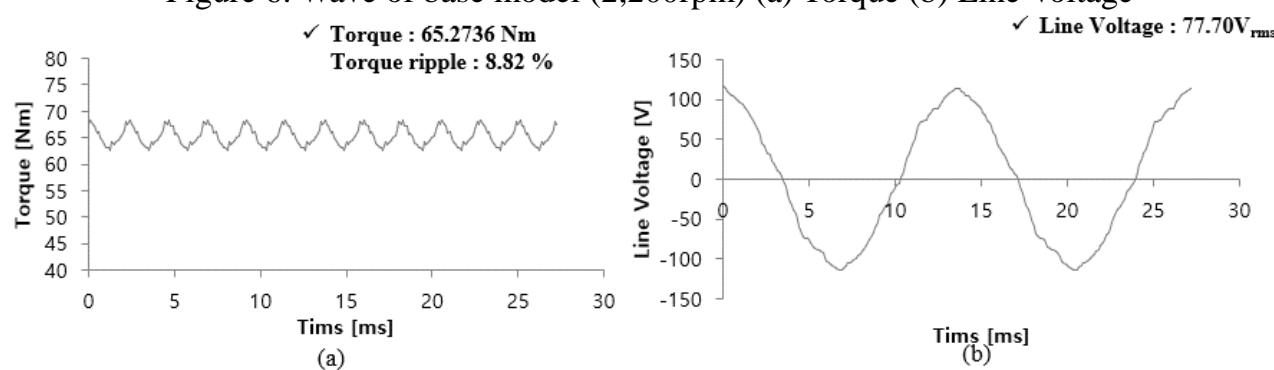

Figure 7. Waveform of skewed model (2,200rpm) (a) Torque (b) Line Voltage 
Figure 8 shows the torque waveform and the line voltage waveform at 6,600rpm of the analytical model. Figure 9 shows the torque and line voltage waveforms for a model with skew applied at 6,600 rpm. Comparing the waveforms of the two models, the torque ripple is lowered due to the reduction of the harmonic even at 6,600 rpm, and the line voltage waveform also shows a smooth waveform.
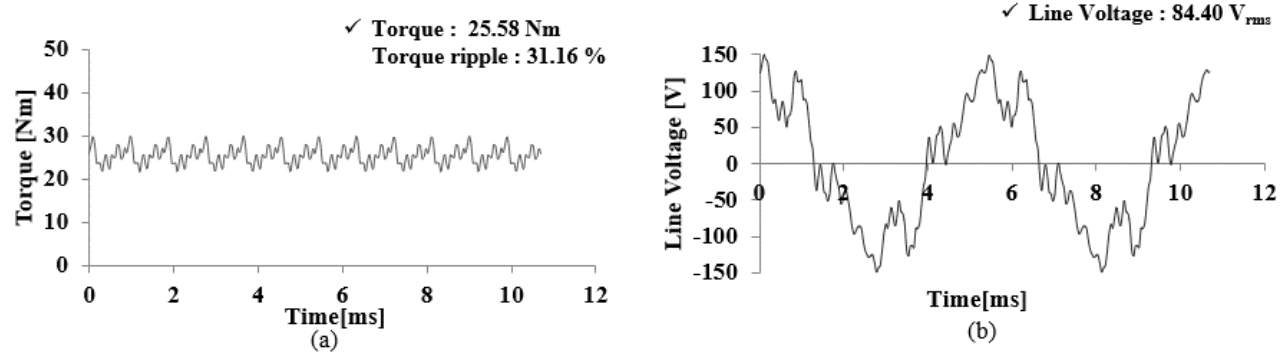

(b)

Figure 8. Wave of base model (6,600rpm) (a) Torque (b) Line Voltage
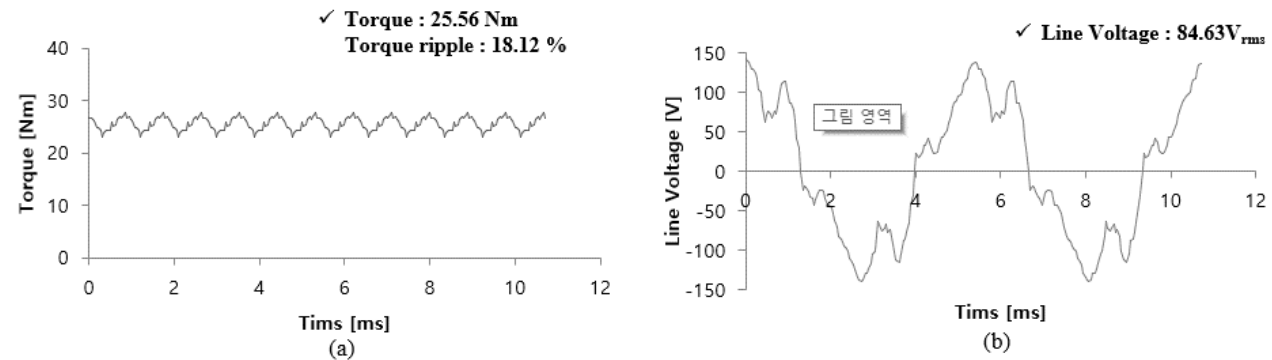

(b)

Figure 9. Waveform of skewed model (6,600rpm) (a) Torque (b) Line Voltage

\section{Conclusion}

In this paper, a study was conducted on the reduction of torque ripple by skew angle and skew stage. Based on the software data, the optimal coefficient level with the lowest cogging torque and THD through the coefficient placement method is a skew angle of 7 degrees and a 3-step skew. Based on this, when applied to the analysis model, the torque ripple and line voltage at the base speed and maximum speed were confirmed. It was confirmed that torque ripple was reduced by reducing harmonics, and it was also confirmed that line voltage waveform showed a smoother waveform.

\section{References}

1. Jin, D. Jung, K. Kim, Y. Chun, H. Lee and J. Lee. (2009) A Study on Improvement Magnetic Torque Characteristics of IPMSM for Direct Drive Washing Machine. IEEE Transactions on Magnetics 45(6), 2811-2814

2. Hyung-Woo Lee, Ki-Doek Lee, Won-Ho Kim, Ik-Sang Jang, Mi-Jung Kim, Jae-Jun Lee, Ju Lee. (2011) Parameter Design of IPMSM With Concentrated Winding Considering Partial Magnetic Saturation. IEEE Transactions on Magnetics 47(10), 3653-3656.

3. Touzhu Li, G. Slemon. (1988) Reduction of cogging torque in permanent magnet motors. IEEE Transactions on Magnetics 24(6), 2901-2903.

4. D. Lin, S. L. Ho, W. N. Fu. (2009) Analytical Prediction of Cogging Torque in Surface-Mounted Permanent-Magnet Motors. IEEE Transactions on Magnetics 45(9), 3296-3302.

5. Sang-Moon Hwang, Jae-Boo Eom, Geun-Bae Hwang, Weui-Bong Jeong, Yoong-Ho Jung. (2000) Cogging torque and acoustic noise reduction in permanent magnet motors by teeth pairing. IEEE Transactions on Magnetics 36(5), 3144-3146.

6. Chunyan Lai, Guodong Feng, Kaushik Mukherjee, Voiko Loukanov, Narayan C. Kar. (2017) Torque Ripple Minimization for Interior PMSM with Consideration of Magnetic Saturation Incorporating Online Parameter Identification. IEEE Transactions on Magnetics 53(6), 8105904.

7. Mohammad Nasir Uddin, Md. Mizanur Rahman. (2019) Online Torque-Flux Estimation-Based Nonlinear Torque and Flux Control Scheme of IPMSM Drive for Reduced Torque Ripples. IEEE Transactions on Power Electronics, 34(1), 636-645.

8. C. Lai, G. Feng, K. Mukherjee, V. Loukanov and N. C. Kar. (2017) Torque Ripple Minimization for Interior PMSM with Consideration of Magnetic Saturation Incorporating Online Parameter Identification. IEEE Transactions on Magnetics 53(6), 1-4. 
9. J. Jung, S. Lee, G. Lee, J. Hong, D. Lee and K. Kim. (2010) Reduction Design of Vibration and Noise in IPMSM Type Integrated Starter and Generator for HEV. IEEE Transactions on Magnetics 46(6), 24542457.

10. C. Lai, G. Feng, K. Mukherjee, V. Loukanov and N. C. Kar. (2018) Torque Ripple Modeling and Minimization for Interior PMSM Considering Magnetic Saturation. IEEE Transactions on Power Electronics 33(3), 2417-2429.

11. Mallick, P. K., Krishna, P., \& Nagargun, A. N. An Image Classification Framework Exploring the Capabilities of Extreme Learning Machines and Artificial Bee Colony. Neural Computing and Applications, https://doi. org/10.1007/s00521-019-04385-5. 